\title{
Standardising the Classification of Harm Associated with Medication Errors: The Harm Associated with Medication Error Classification (HAMEC)
}

\author{
Peter J. Gates ${ }^{1}$ (D) Melissa T. Baysari ${ }^{1}$ - Virginia Mumford ${ }^{1} \cdot$ Magdalena Z. Raban $^{1} \cdot$ Johanna I. Westbrook $^{1}$
}

Published online: 23 April 2019

(c) The Author(s) 2019

\begin{abstract}
Classifying harm associated with a medication error can be time consuming and labour intensive and limited studies undertake this step. There is no standardised process, and few studies that report harm assessment provide adequate methods to allow for study replication. Studies typically mention that a clinical review panel classified patient harm and provide a reference to a classification tool. Moreover, in many studies it is unclear whether potential or actual harm was classified as studies refer only to 'error severity'. The tools used to categorise the severity of patient harm vary widely across studies and few have been assessed for inter-rater reliability and criterion validity. In this paper, we describe the systematic process we undertook to synthesise the defining elements and strengths, while mitigating the limitations, of existing harm classification tools to derive the Harm Associated with Medication Error Classification (HAMEC). This new tool provides a harm classification for use across clinical and research settings. The provision of an explicit process for its application and guiding category descriptors are designed to reduce the risk of misclassification and produce results that are comparable across studies. As the World Health Organisation embarks on its international safety challenge of reducing medication-related harm by $50 \%$, accompanying methodological advances are required to measure progress.
\end{abstract}

\section{Introduction}

The World Health Organisation (WHO) announced the third Global Patient Safety Challenge as 'medication without harm' in 2017 [1]. The Challenge presents the ambitious target to "reduce the level of severe, avoidable harm related to medication by $50 \%$ over 5 years, globally". Assessing efforts to meet this challenge requires accurate information on the prevalence and consequence of medication errors (defined as unintended failure in the drug treatment process that leads to, or has the potential to lead to, harm to the patient [2]). Over the last two decades, the prevalence of medication errors has been the focus of a

Electronic supplementary material The online version of this article (https://doi.org/10.1007/s40264-019-00823-4) contains supplementary material, which is available to authorized users.

Peter J. Gates

Peter.gates@mq.edu.au

Centre for Health Systems and Safety Research, Australian Institute of Health Innovation, Macquarie University, Sydney, NSW, Australia

\section{Key Points}

There is great diversity in the definitions of, and methods used for classifying, medication-related harm in hospitals.

Comparisons of the severity of medication-related harm across studies and clinical settings are limited by inconsistency in the tools used for the classification of medication-related harm.

We propose the Harm Associated with Medication Error Classification (HAMEC) tool, a new tool derived from the common nomenclature used to label and define levels of medication-related harm.

HAMEC includes clear definitions and does not include examples of error, harm or treatments, which are prone to misinterpretation. 
large body of work, with systematic reviews targeting studies of neonates [3-5], children [6, 7], adults [8-11] and the elderly [12]. Where pooled estimates are provided, the rate of medication errors is estimated to occur in $10-20 \%$ of medication orders $[7,8,10,11]$. The disparate medication error rates reported across studies have been attributed to diversity in the definition of errors [13-15], the methods used for their detection and classification [16-18], and the chosen denominator of prevalence [19]. In contrast, research on the consequence of medication errors, namely the extent to which medication errors cause harm (including injury, damage or illness), or have the potential to cause harm, is relatively scant [20-22]. A review of the prevalence of medication-related harm estimates that $<10 \%$ of inpatients will experience such harm, though variation across studies in the definition of what constitutes harm is consistently cited [20, 23, 24]. Standardising the definition of harm associated with medication errors [15], and the development and implementation of tools to measure harm are important patient safety priorities [25].

The assessment of harm associated with medication errors typically involves two fundamental components: the identification of potential or actual patient harm (hereby referred to as any harm) related to a medication event; and the classification of the degree or seriousness of that harm. Identifying any harm associated with medication errors can be time consuming and labour intensive, and there is no standardised process [16]. Assessing potential and actual harm are separate processes, each with unique challenges. It has been suggested that both processes ideally involve a panel, usually comprised of pharmacists, nurses and/or medical clinicians [16]. When assessing potential harm, the panel considers whether the error would normally be expected to cause harm to a patient, or if the panel has access to information regarding a patient's clinical status, this can be used to inform what level of harm would be expected in that patient. This process is undertaken regardless of whether the specific error being assessed reached the patient. In contrast, actual harm can only be classified in situations where the patient experienced the error (e.g. the incorrect dose was administered to the patient). This classification requires specific information about the circumstances of the patient receiving the error and the actual harm. Once a potential or actual harm is identified, the degree or seriousness of harm can be classified. This classification relies on the quality of information recorded in patient records. Unfortunately, poor record quality is consistently cited to be a significant limitation in assessing adverse drug events [26-38]. The difficulty of classifying either potential or actual harm is reflected in reports of low inter-rater reliability among clinicians [39-41], although experience as a clinician, and engaging more than two clinicians has been shown to improve the consistency of these ratings [42].

An important, though infrequently employed step when assessing patient harm associated with a medication event involves considering the likely probability that the identified harms are causally linked to the medication error [16, $24,43-52]$. This causality assessment is typically completed with the use of a confidence tool; most frequently the Naranjo Algorithm [53], or the World Health Organization-Uppsala Monitoring Centre criteria [54]. Here, it is not the level of confidence that is important per se, but rather that a possible association between the medication error and the identified harm is established $[55,56]$.

Learning from previous studies that have classified the seriousness of medication-related harm is challenging as few studies have documented the exact processes used. Instead, studies typically mention that a clinical review panel classified harm, and provide a reference to a classification tool such as the National Coordinating Council for Medication Error Reporting and Prevention index (the NCC MERP [57]). In addition, widespread inconsistency in the terms used to define medication errors and the harm associated with medication errors make reporting and comparing research findings difficult [15]. Although significant efforts to provide standard definitions of medication errors and related harm have been made, for example the EU regulatory network has recently published a good practice guide [58], no standard tool for the classification of medicationrelated harm has been widely adopted. This is important as the use of a single tool across settings would contribute to the identification of trends in the kinds of errors that cause patient harm and provide focus to prevention efforts.

A review of the harm classification tools employed prior to 2013 identified 40 different classification tools among 61 studies of prescribing errors [39]. That review sought to identify tools with acceptable inter-rater reliability $(\kappa>0.7)$ and criterion validity (involving comparison of reviewer judgments of potential harm against actual harm measured in situations where the actual harm was known). Only two tools met this criteria: the NCC MERP for classifying actual harm [57] and Dean and Barber's 10-point Likert scale for classifying potential harm [59]. However, these tools have also been the subject of some criticism [39].

The initial reliability testing of the NCC MERP was conducted under controlled conditions involving a panel of trained professionals (mostly pharmacists) classifying the actual harm associated with 27 medication errors identified in incident reports [60]. That study reported 'substantial' inter-rater agreement $(\kappa=0.61)$; however, the review panel reported being confused by the individual category definitions [60]. When presented with a modified scale (with categories $\mathrm{C}$ and $\mathrm{D}$ combined, and $\mathrm{E}, \mathrm{F}$ and $\mathrm{H}$ combined-see the Electronic Supplementary Material [ESM]), the panel 
inter-rater reliability improved $(\kappa=0.74)$ [60]. In a study designed to determine if high inter-rater reliability could be obtained when the tool was used in everyday practice, the reliability was found to be fair $(\kappa<0.4)$ [40]. That study included a review panel of pharmacists and physicians who used the NCC MERP to classify actual harm associated with 30 medication errors identified by chart review.

Some author groups have discussed the limitations of Dean and Barber's tool, including concerns that it is too time consuming to apply [39], and requires at least four reviewers to achieve an acceptable generalisability coefficient $(>0.8)$ [59]. Neither Dean and Barber's tool nor the NCC MERP have been widely used in studies outside of the UK or US, respectively.

No tool for the classification of medication-related harm has been recommended for use across clinical and research settings. Therefore, there is scope for a new tool to be developed; designed with the goal of standardising the classification of harm severity associated with medication errors. In this article, we summarise the lack of standardisation in the process of classifying potential and/or actual patient harm following a medication error and propose a way forward. We begin by identifying inconsistencies in the nomenclature used across studies that have assessed harm. We then identify the similarities between the tools and the published protocols for their use and highlight limitations of these tools. Finally, we propose a new tool for the classification of potential and actual patient harm that addresses these limitations and describe its development.

\section{Inconsistencies in the Nomenclature Associated with Harm Assessment}

\subsection{Error Severity}

The current convention is to cite 'error severity' when referring to the extent of the potential or actual impact of medication errors. However, this term does not refer to the error as such, but to the potential or actual patient harm thought to be associated with the error. Thus, the common practice of reporting that the 'prevalence and severity of medication errors were investigated' (particularly in study abstracts) often does not make it clear whether potential or actual patient harm was assessed. Making this distinction clear is important given the obvious gravity of an actual patient harm event over potential for harm. Further, as many errors are intercepted before reaching the patient, errors that actually cause harm make up only a small fraction of the errors with the potential to cause harm [20].

\subsection{Classification of Potential Harm}

Different author groups have referred to harm that could be potentially caused by a medication error in various (often interchangeable) and inconsistent ways. These include 'likely harm' [61, 62], a 'potential consequence' [63, 64], an 'assumed consequence' [65], 'predicted outcome' [66], 'potential risk' [67-69], and/or 'potential severity' [70]. Adding to this inconsistency are studies that refer to errors with the potential to harm a patient as either "clinically significant' [61, 71-75], 'major' [70, 76-78], 'serious' [42] [79, 80], 'important' [81], 'problematic' [74] and/or 'high risk' [82]. Essentially, each of these terms reflects a classification of potential patient harm into two broad levels of 'severity'. That is, the error is called significant/major (potential for harm) or insignificant/minor (no or little potential for harm).

Potential harm caused by a medication error could be confused with 'potential adverse drug events', or 'near misses'. The latter are defined as medication errors with the potential for injury but in which no injury occurred due to either patient circumstance or an intervention [83, 84]. That is, a random break in the chain of events leading up to a potential adverse event that has prevented injury, damage, illness or harm, but the potential for harm was nonetheless very near [2].

\subsection{Classification of Actual Harm}

Classifying actual harm that was caused by a medication error typically involves identifying the severity of patient harm caused by the error that has been observed or documented to have occurred. Across studies, actual harm has been referred to as either the 'medication error outcome' [85, 86], 'patient outcome' [87], 'patient sequelae' [88], 'error consequence' [89], 'resulting harm' [90], 'related harm' [89], 'adverse drug event' [44, 91, 92], 'patient injury' [45], and/or 'error repercussion' [93]. Notably, the 'outcome', 'sequelae' or 'consequence' across these studies referred to either patient harm [86, 88], the levels of care required to respond to the harm $[87,89]$, or both [85].

\section{Review of Published Harm Classification Tools}

Following systematic reviews of the literature on potential and actual harm [24], and dose errors [22], and an additional targeted non-systematic literature review (detailed in ESM 1), we identified almost fifty different tools for classifying the level of potential or actual harm associated with medication errors. Each of these tools and the associated guidelines for their use are detailed in ESM 2. With the exception of 
Dean and Barber's 10-point tool [59], these tools classify harm into at least three levels, typically four or five levels, and up to seven levels. As detailed in ESM 1, the most frequently used labels of harm were, consecutively, 'minor', 'moderate', 'serious', 'severe', 'life threatening' and 'death'.

Each level of harm is often accompanied by a list of situations that exemplify the level of harm severity. These situations are either examples of medication errors (such as an overdose), harms (such as a temporary low-grade pain), or the level of care required to respond to a harm (such as additional monitoring). The tools that provided examples of medication errors were typically published prior to 2000 . For example, in order to guide researchers in the use of their harm classification tool published in 1987, Folli and colleagues suggest that the potential harm from a "less than four times overdose of a drug with low therapeutic index" be considered 'significant', while the potential harm from a "more than 10 times overdose of a chemotherapy agent" be considered 'lethal' [94]. In studies providing examples of actual harm, two dimensions of harm are typically considered. That is, harm permanence (temporary versus permanent harm), and the extent of harm (variously described by rating distress or inconvenience, up to loss of function, quality of life or death and/or by signs of disability, toxicity, or disease). For example, Gokhul and colleagues [86] suggest that "rash or diarrhoea" is a 'significant' harm while "bleeding or an altered mental state" is 'serious'. Many harm classification tools provide examples of the level of care required to respond to a harm experienced to exemplify levels of harm severity. These tools reference changes in treatment plans, prolonged length of hospital stay, and intensiveness of treatments (from monitoring to surgery). For example, the NCC-MERP distinguishes between errors that result in harm that required intervention or prolonged hospitalisation, from those that required interventions necessary to sustain life [57].

\subsection{Limitations of Harm Classification Tools}

Each of the identified tools are designed to assess either potential or actual harm. The difference can be discerned from the language used, where potential harm tools refer to 'likely' outcomes while tools designed to assess actual harm refer to actual consequences. Despite this difference, many researchers employ tools that were designed to assess actual harm to assess potential harm and vice versa. For example, the frequently cited NCC-MERP tool for classifying actual patient harm has been used to assess both potential harm [61, 62, 95] and actual harm [85, 87, 90, 92, 96-102], and has also been used to 'categorise errors' without explicitly identifying whether potential or actual harm was assessed [103-107]. As such, comparisons between study results using the same harm classification tool are muddied by inconsistencies in either the use of the tools, or a lack of information about whether actual or potential harm was assessed.

The utility of providing examples of medication errors, harms or treatments as a means of ensuring consistent tool use may be limited. This is because not all clinicians may agree with the level of harm assigned to an example and instead perceive that the example typifies a less or more 'severe' harm. As a result, inconsistent clinician ratings are a frequent occurrence and highlights the need for processes to achieve reviewer consensus [42].

Finally, the use of these tools is limited by the availability of information on patient harm and the corresponding treatments documented in patient records [40]. That is, using a tool that classifies harm based on the treatments administered to a patient requires all such actions to be documented to ensure an accurate classification of harm. Importantly, the occurrence of these actions relies on the detection of the medication error during the admission. Previous studies have shown low levels of detection and high rates of under-reporting of medication incidents by hospital staff [108-110]. Minor to moderate consequences from medication errors are also less likely to be detected and therefore not monitored or documented [110]. Thus, unless the panel assessing harm accounts for whether the medication error was detected, assessment of actual harm will be biased towards non-minor harms. Finally, assessing actual harm requires information on the individual patient and the treatment received to be documented, and the poor quality of this information is frequently described to be a significant limitation [26-38, 111].

\section{Proposed Harm Assessment Tools for Classifying Potential and Actual Harm Severity Related to Medication Errors}

Our proposed harm assessment tools were designed using a systematic approach (detailed in ESM 1). As a first step, we selected the nomenclature used to label and define the levels of harm severity that is most common among existing tools, but that did not include examples of error, harm or treatments that could be misinterpreted. Next, we assessed the guidance associated with existing tools and chose examples of harms and corresponding treatments that were the least open to misclassification. Finally, we used the NCC-MERP [57] as the framework for an iterative revision process based on the outcomes of several workshops and harm assessment panels. These panels assessed real examples of medication errors as part of our ongoing randomised controlled trial of the effectiveness of an electronic medication management 
Table 1 The Harm Associated with Medication Errors Classification (HAMEC): potential harm

\begin{tabular}{|c|c|c|}
\hline Level & Reference & Description \\
\hline 0 & No harm & No potential for patient harm, nor any change in patient monitoring, level or length of care required \\
\hline 1 & Minor & $\begin{array}{l}\text { There was potential for minor, non-life threatening, temporary harm that may or may not require efforts to assess for a change } \\
\text { in a patient's condition such as monitoring }{ }^{\text {a }} \text {. These efforts may or may not have potentially caused minimal increase in } \\
\text { length of care }(<1 \text { day) }\end{array}$ \\
\hline 2 & Moderate & $\begin{array}{l}\text { There was potential for minor, non-life threatening, temporary harm that would require efforts to assess for a change in a } \\
\text { patient's condition such as monitoring }{ }^{\mathrm{a}} \text {, and additional low-level change in a patient's level of care }{ }^{\mathrm{b}} \text { such as a blood test. }^{\text {and }} \text { any potential increase in the length of care is likely to be minimal }(<1 \text { day) }\end{array}$ \\
\hline 3 & Serious & $\begin{array}{l}\text { There was potential for major, non-life threatening, temporary harm, or minor permanent harm }{ }^{c} \text { that would require a high } \\
\text { level of care }{ }^{b} \text { such as the administration of an antidote. An increase in the length of care of } \geq 1 \text { day is expected }\end{array}$ \\
\hline 4 & Severe & $\begin{array}{l}\text { There was potential for life-threatening or mortal harm, or major permanent harm }{ }^{\mathrm{c}} \text { that would require a high level of care } \\
\text { such as the administration of an antidote or transfer to intensive care. A substantial increase in the length of care of }>1 \text { day } \\
\text { is expected }\end{array}$ \\
\hline
\end{tabular}

${ }^{a}$ Monitoring refers to the minimally intrusive observation of the patient's condition over time. Observations are typically made for urine output, general level of consciousness, or vital signs including heart or breathing rate

${ }^{b}$ Level of care refers to the degree of active treatments that are initiated in response to actual or potential change in the patient's condition

${ }^{c}$ Permanent harm is such that, as a consequence of the drug event, the patient would require ongoing care, or experience an ongoing disability, beyond the index admission

system introduced to reduce medication errors and medication-related harm in two paediatric hospitals [50].

Following the work of Morimoto and colleagues [16], we recommend that the panel using our proposed tool comprise at least three members from multiple professions (usually pharmacists, nurses and medical clinicians) with majority consensus reached via discussion led by a panel chairperson.

\subsection{The Harm Associated with Medication Error Classification (HAMEC)}

Prior to classifying harm severity with the Harm Associated with Medication Error Classification (HAMEC) tool, the process of confirming that a medication error occurred (sometimes referred to as determining error preventability), and that harm was at least possibly associated with the error (referred to as the causality assessment), is expected to have been completed. When classifying the severity of potential harm associated with a medication error using the HAMEC (see Table 1), the panel is instructed to assume that the error was undetected and reached the patient. The panel does not necessarily need to consider the specific clinical context of the individual patient involved. That is, the panel is asked "regardless of patient circumstance, what level of harm would this medication error be expected to cause to a patient"? If the clinical status of the patient is known to

Table 2 The Harm Associated with Medication Errors Classification (HAMEC): actual harm

\begin{tabular}{|c|c|c|}
\hline Level & Reference & Description \\
\hline 0 & No harm & There was no actual patient harm, nor any change in patient monitoring, level or length of care required \\
\hline 1 & Minor & $\begin{array}{l}\text { There was actual minor, non-life threatening, temporary harm that may or may not have required efforts to assess for a change } \\
\text { in a patient's condition such as monitoring. These efforts may or may not have actually caused minimal increase in length } \\
\text { of care }(<1 \text { day) }\end{array}$ \\
\hline 2 & Moderate & $\begin{array}{l}\text { There was actual minor, non-life threatening, temporary harm that did require efforts to assess for a change in a patient's } \\
\text { condition such as monitoring }{ }^{\mathrm{a}} \text {, and additional low-level change in a patient's level of care }{ }^{\mathrm{b}} \text { such as a blood test. Any actual } \\
\text { increase in the length of care was minimal }(<1 \text { day) }\end{array}$ \\
\hline 3 & Serious & $\begin{array}{l}\text { There was actual major, non-life threatening, temporary harm, or minor permanent harm }{ }^{\mathrm{c}} \text { that required a high level of care } \\
\text { such as the administration of an antidote. An increase in the length of care of } \geq 1 \text { day occurred }\end{array}$ \\
\hline 4 & Severe & $\begin{array}{l}\text { There was actual life-threatening or mortal harm, or major permanent harm }{ }^{\mathrm{c}} \text { that required a high level of care }{ }^{\mathrm{b}} \text { such as the } \\
\text { administration of an antidote or transfer to intensive care. A substantial increase in the length of care of }>1 \text { day occurred }\end{array}$ \\
\hline
\end{tabular}

${ }^{a}$ Monitoring refers to the minimally intrusive observation of the patient's condition over time. Observations are typically made for urine output, general level of consciousness, or vital signs including heart or breathing rate

${ }^{b}$ Level of care refers to the degree of active treatments that are initiated in response to actual or potential change in the patient's condition

${ }^{c}$ Permanent harm is such that, as a consequence of the drug event, the patient required ongoing care, or experiences an ongoing disability, beyond the index admission 
the panel, this information can be used to inform the classification and the panel is asked "what level of harm would this medication error be expected to cause this patient". In contrast, use of the HAMEC to classify actual harm severity (see Table 2) assumes that a medication error occurred, reached the patient, and harm was identified. When classifying the degree of actual harm, the harm assessment panel must take into consideration the patient's age, comorbidities and overall condition.

\section{Conclusion}

To further our understanding of the impact of medication errors on patient safety, we need to go beyond just measuring the frequency of errors and assess the severity of harm associated with those errors. However, to date the process of classifying this harm has been fraught with inconsistencies and lacks standardisation. Indeed, the frequent use of the term 'error severity' invites confusion as, without further clarification, it remains unclear if potential or actual patient harm was assessed. We propose that the term 'error severity', in the absence of specifying what outcome is being assessed, is misleading and suggest future research instead refer to the classification of potential or actual harm associated with a medication error. Following the synthesis of the defining elements from existing tools for classifying harm, we have developed the HAMEC, a tool that allows for the classification of harm across clinical and research settings. While the HAMEC offers a more structured framework for further discussion, validation is required.

Acknowledgements We would like to thank Erin Fitzpatrick, Ahmed Abo Salem, Cinny Dong, Gary Roberts, and Renee Quirk, our team of pharmacists, for their efforts in pilot testing the Harm Associated with Medication Error Classification tool.

\section{Compliance with Ethical Standards}

Conflict of interest Peter Gates, Melissa Baysari, Magdalena Raban, Virginia Mumford, and Johanna Westbrook have no conflicts of interest that are directly relevant to the content of this study.

Funding Funding from a National Health and Medical Research Council Partnership Grant (APP1094878) was used to assist with this research. MZR is supported by a National Health and Medical Research Council Early Career Fellowship (APP1143941).

Open Access This article is distributed under the terms of the Creative Commons Attribution-NonCommercial 4.0 International License (http://creativecommons.org/licenses/by-nc/4.0/), which permits any noncommercial use, distribution, and reproduction in any medium, provided you give appropriate credit to the original author(s) and the source, provide a link to the Creative Commons license, and indicate if changes were made.

\section{References}

1. Donaldson LJ, Kelley ET, Dhingra-Kumar N, Kieny M-P, Sheikh A. Medication without harm: WHO's Third Global Patient Safety Challenge. Lancet. 2017;389(10080):1680-1. https://doi. org/10.1016/S0140-6736(17)31047-4.

2. Pharmacovigilance Risk Assessment Committee. Good practice guide on recording, coding, reporting and assessment of medication errors (EMA/762563/2014). 2015. http://www.ema.europ a.eu/docs/en_GB/document_library/Regulatory_and_procedural _guideline/2015/11/WC500196979.pdf. Accessed 18 Jan 2018.

3. Stavroudis TA, Miller MR, Lehmann CU. Medication errors in neonates. Clin Perinatol. 2008;35(1):141-61. https://doi. org/10.1016/j.clp.2007.11.010.

4. Santesteban E, Arenas S, Campino A. Medication errors in neonatal care: a systematic review of types of errors and effectiveness of preventive strategies. J Neonatal Nurs. 2015;21(5):200-8. https://doi.org/10.1016/j.jnn.2015.04.002.

5. Snijders C, Van Lingen RA, Molendijk A, Fetter WPF. Incidents and errors in neonatal intensive care: a review of the literature. Arch Dis Child Fetal Neonatal Ed. 2007;92(5):F391-8. https:// doi.org/10.1136/adc.2006.106419.

6. Ghaleb MA, Barber N, Franklin BD, Yeung VWS, Khaki ZF, Wong ICK. Systematic review of medication errors in pediatric patients. Ann Pharmacother. 2006;40(10):1766-76. https://doi. org/10.1345/aph.1G717.

7. Koumpagioti D, Varounis C, Kletsiou E, Nteli C, Matziou V. Evaluation of the medication process in pediatric patients: a meta-analysis. Jornal de Pediatria. 2014;90(4):344-55.

8. Keers RN, Williams SD, Cooke J, Ashcroft DM. Prevalence and nature of medication administration errors in health care settings: a systematic review of direct observational evidence. Ann Pharmacother. 2013;47(2):237-56. https://doi.org/10.1345/ aph.1R147.

9. Carlton G, Blegen MA. Medication-related errors: a literature review of incidence and antecedents. Annu Rev Nurs Res. 2006;24(C2):19-38.

10. Lewis PJ, Dornan T, Taylor D, Tully MP, Wass V, Ashcroft DM. Prevalence, incidence and nature of prescribing errors in hospital inpatients: a systematic review. Drug Saf. 2009;32(5):379-89. https://doi.org/10.2165/00002018-200932050-00002.

11. Berdot S, Gillaizeau F, Caruba T, Prognon P, Durieux P, Sabatier B. Drug administration errors in hospital inpatients: a systematic review. PLoS One. 2013;8(6):e68856. https://doi.org/10.1371/ journal.pone.0068856.

12. Fialová D, Onder G. Medication errors in elderly people: contributing factors and future perspectives. $\mathrm{Br} \mathrm{J}$ Clin Pharmacol. 2009;67(6):641-5. https://doi.org/10.111 1/j.1365-2125.2009.03419.x.

13. Lisby M, Nielsen LP, Brock B, Mainz J. How are mediation errors defined? A systematic literature review of definitions and characteristics. Int J Qual Health Care. 2010;22(6):507-18.

14. Ferner RE, Aronson JK. Clarification of terminology in medication errors: definitions and classification. Drug Saf. 2006;29(11):1011-22.

15. Falconer N, Barras M, Martin J, Cottrell N. Defining and classifying terminology for medication harm: a call for consensus. Eur J Clin Pharmacol. 2018. https://doi.org/10.1007/s0022 8-018-2567-5.

16. Morimoto T, Gandhi T, Seger A, Hsieh T, Bates D. Adverse drug events and medication errors: detection and classification methods. Qual Saf Health Care. 2004;13(4):306-14. https://doi. org/10.1136/qshc.2004.010611. 
17. Aronson JK. Medication errors: definitions and classification. Br J Clin Pharmacol. 2009;67(6):599-604. https://doi.org/10.11 11/j.1365-2125.2009.03415.x.

18. Manias E. Detection of medication-related problems in hospital practice: a review. Br J Clin Pharmacol. 2013;76(1):7-20.

19. Ferner RE. The epidemiology of medication errors: the methodological difficulties. Br J Clin Pharmacol. 2009;67(6):614-20. https://doi.org/10.1111/j.1365-2125.2009.03417.x.

20. von Laue NC, Schwappach DLB, Koeck CM. The epidemiology of preventable adverse drug events: a review of the literature. Wien Klin Wochenschr. 2003;115(12):407-15. https://doi. org/10.1007/BF03040432.

21. Jordan S, Logan PA, Panes G, Vaismoradi M, Hughes D. Adverse drug reactions, power, harm reduction, regulation and the ADRe profiles. Pharmacy (Basel, Switzerland). 2018;6(3):e102. https:// doi.org/10.3390/pharmacy6030102.

22. Gates PJ, Meyerson SA, Baysari MT, Westbrook JI. The prevalence of dose errors among paediatric patients in hospital wards with and without health information technology: A systematic review and meta-analysis. Drug Saf. 2018. https://doi. org/10.1007/s40264-018-0715-6.

23. Wilmer A, Louie K, Dodek P, Wong H, Ayas N. Incidence of medication errors and adverse drug events in the ICU: a systematic review. Qual Saf Health Care. 2010;19(5):e7.

24. Gates PJ, Meyerson SA, Baysari MT, Lehmann CU, Westbrook JI. Preventable adverse drug events among inpatients: a systematic review. Pediatrics. 2018;142(3):e20180805. https://doi. org/10.1542/peds.2018-0805.

25. Bates DW, Singh H. Two decades since To Err Is Human: an assessment of progress and emerging priorities in patient safety. Health Aff. 2018;37(11):1736-43. https://doi.org/10.1377/hltha ff.2018.0738.

26. Michel P, Quenon JL, de Sarasqueta AM, Scemama O. Comparison of three methods for estimating rates of adverse events and rates of preventable adverse events in acute care hospitals. BMJ. 2004;328(7433):199. https://doi.org/10.1136/bmj.328.7433.199.

27. Lilford RJ, Mohammed MA, Braunholtz D, Hofer TP. The measurement of active errors: methodological issues. Qual Saf Health Care. 2003;12(suppl 2):ii8.

28. Thomas EJ, Petersen LA. Measuring errors and adverse events in health care. J Gen Intern Med. 2003;18(1):61-7. https://doi. org/10.1046/j.1525-1497.2003.20147.x.

29. Vleugels A, Gillet P, Van den Heede K, Jacques J, Kolh P, Sermeus W, et al. Retrospective medical record evaluation: reliability in assessing causation, preventability, and disability of adverse events. Int J Health Care Qual Assur. 2012;25(8):649_ 62. https://doi.org/10.1108/09526861211270613.

30. Brennan TA, Leape LL, Laird NM, Hebert L, Localio AR, Lawthers AG, et al. Incidence of adverse events and negligence in hospitalized patients. N Engl J Med. 1991;324(6):370-6. https ://doi.org/10.1056/NEJM199102073240604.

31. Department of Health and Human Services. Adverse events in hospitals: National incidence among medicare beneficiaries. Washington, DC. 2010.

32. James JT. A new, evidence-based estimate of patient harms associated with hospital care. J Patient Saf. 2013;9(3):122-8. https:// doi.org/10.1097/PTS.0b013e3182948a69.

33. Weissman JS, Schneider EC, Weingart SN, Epstein AM, DavidKasdan J, Feibelmann S, et al. Comparing patient-reported hospital adverse events with medical record review: do patients know something that hospitals do not? Ann Intern Med. 2008;149(2):100-8.

34. Wilson RM, Runciman WB, Gibberd RW, Harrison BT, Newby L, Hamilton JD. The quality in australian health care study. The Medical journal of Australia. 1995;163(9):458-71.
35. Koran LM. The reliability of clinical methods, data and judgments (first of two parts). N Engl J Med. 1975;293(13):642-6. https://doi.org/10.1056/nejm197509252931307.

36. Koran LM. The reliability of clinical methods, data and judgments (second of two parts). N Engl J Med. 1975;293(14):695701. https://doi.org/10.1056/nejm197510022931405.

37. Localio AR, Weaver SL, Landis JR, Lawthers AG, Brenhan TA, Hebert L, et al. Identifying adverse events caused by medical care: degree of physician agreement in a retrospective chart review. Ann Intern Med. 1996;125(6):457-64.

38. Vincent C, Neale G, Woloshynowych M. Adverse events in British hospitals: preliminary retrospective record review. BMJ. 2001;322(7285):517-9. https://doi.org/10.1136/ bmj.322.7285.517.

39. Garfield S, Reynolds M, Dermont L, Franklin BD. Measuring the severity of prescribing errors: a systematic review. Drug Saf. 2013;36(12):1151-7.

40. van Doormaal JE, Mol PG, van den Bemt PM, Zaal RJ, Egberts AC, Kosterink JG, et al. Reliability of the assessment of preventable adverse drug events in daily clinical practice. Pharmacoepidemiol Drug Saf. 2008;17(7):645-54. https://doi.org/10.1002/ pds.1586.

41. Haynes K, Hennessy S, Morales KH, Gibson GA, Barnhart C, Jaipaul CK, et al. Inter-rater reliability of a classification system for hospital adverse drug event reports. Clin Pharmacol Ther. 2008;83(3):485-8. https://doi.org/10.1038/sj.clpt.6100322.

42. Walsh KE, Harik P, Mazor KM, Perfetto D, Anatchkova M, Biggins $\mathrm{C}$, et al. Measuring harm in health care: optimizing adverse event review. Med Care. 2017;55(4):436-41.

43. Benkirane RR, Abouqal R, Haimeur CC, SS SECEK, Azzouzi AA, Mdaghri Alaoui AA et al. Incidence of adverse drug events and medication errors in intensive care units: a prospective multicenter study. J Patient Saf. 2009;5(1):16-22.

44. Dedefo MG, Mitike AH, Angamo MT. Incidence and determinants of medication errors and adverse drug events among hospitalized children in West Ethiopia. BMC Pediatr. 2016. https:// doi.org/10.1186/s12887-016-0619-5.

45. Fortescue EB, Kaushal R, Landrigan CP, McKenna KJ, Clapp $\mathrm{MD}$, Federico F, et al. Prioritizing strategies for preventing medication errors and adverse drug events in pediatric inpatients. Pediatrics. 2003;111(4 Pt 1):722-9.

46. Gazarian M, Graudins LV. Long-term reduction in adverse drug events: an evidence-based improvement model. Pediatrics. 2012;129(5):e1334-42. https://doi.org/10.1542/peds.2011-1902.

47. Kaushal R, Bates DW, Abramson EL, Soukup JR, Goldmann DA. Unit-based clinical pharmacists' prevention of serious medication errors in pediatric inpatients. Am J Health Syst Pharm. 2008;65(13):1254-60. https://doi.org/10.2146/ajhp070522.

48. Kunac DL, Reith DM. Preventable medication-related events in hospitalised children in New Zealand. N Z Med J. 2008;121(1272):17-32.

49. Rashed AN, Neubert A, Tomlin S, Jackman J, Alhamdan H, AlShaikh A, et al. Epidemiology and potential associated risk factors of drug-related problems in hospitalised children in the United Kingdom and Saudi Arabia. Eur J Clin Pharmacol. 2012;68(12):1657-66.

50. Rashed AN, Wilton L, Lo CCH, Kwong BYS, Leung S, Wong ICK. Epidemiology and potential risk factors of drug-related problems in Hong Kong paediatric wards. Br J Clin Pharmacol. 2014;77(5):873-9. https://doi.org/10.1111/bcp.12270.

51. Nebeker JR, Barach P, Samore MH. Clarifying adverse drug events: a clinician's guide to terminology, documentation, and reporting. Ann Intern Med. 2004;140(10):795-801.

52. Gandhi TK, Weingart SN, Borus J, Seger AC, Peterson J, Burdick E, et al. Adverse drug events in ambulatory care. N Engl J Med. 2003;348(16):1556-64. https://doi.org/10.1056/NEJMsa020703. 
53. Naranjo CA, Busto U, Sellers EM, Sandor P, Ruiz I, Roberts EA, et al. A method for estimating the probability of adverse drug reactions. Clin Pharmacol Ther. 1981;30(2):239-45.

54. World Health Organization Uppsala Monitoring Centre. The use of the WHO-UMC system for standardised case causality assessment. http://www.who.int/medicines/areas/quality_safety/ safety_efficacy/WHOcausality_assessment.pdf. Accessed 1 May 2017.

55. Kane-Gill SL, Forsberg EA, Verrico MM, Handler SM. Comparison of three pharmacovigilance algorithms in the ICU setting: a retrospective and prospective evaluation of ADRs. Drug Saf. 2012;35(8):645-53. https://doi.org/10.2165/11599730-00000 0000-00000.

56. Belhekar MN, Taur SR, Munshi RP. A study of agreement between the Naranjo algorithm and WHO-UMC criteria for causality assessment of adverse drug reactions. Indian J Pharmacol. 2014;46(1):117-20. https://doi.org/10.4103/0253-7613.125192.

57. National Coordinating Council for Medication Error Reporting and Prevention (NCCMERP). NCC MERP Index for categorizing medication errors. NCCMERP. 1996. http://www.nccme rp.org/types-medication-errors. Accessed 5 Jan 2018.

58. Goedecke T, Ord K, Newbould V, Brosch S, Arlett P. Medication errors: new EU good practice guide on risk minimisation and error prevention. Drug Saf. 2016;39(6):491-500. https://doi. org/10.1007/s40264-016-0410-4.

59. Dean BS, Barber ND. A validated, reliable method of scoring the severity of medication errors. AJHP. 1999;56(1):57-62.

60. Forrey RA, Pedersen CA, Schneider PJ. Interrater agreement with a standard scheme for classifying medication errors. AJHP. 2007;64(2):175-81. https://doi.org/10.2146/ajhp060109.

61. Bobb A, Gleason K, Husch M, Feinglass J, Yarnold PR, Noskin GA. The epidemiology of prescribing errors: the potential impact of computerized prescriber order entry. Arch Intern Med. 2004;164(7):785-92.

62. Lyons I, Furniss D, Blandford A, Chumbley GM, Iacovides I, Wei $\mathrm{L}$ et al. Errors and discrepancies in the administration of intravenous infusions: a mixed methods multihospital observational study. BMJ Qual Saf. 2018. https://doi.org/10.1136/bmjqs -2017-007476.

63. Lisby M, Nielsen LP, Mainz J. Errors in the medication process: frequency, type, and potential clinical consequences. Int J Qual Health Care. 2005;17(1):15-22. https://doi.org/10.1093/intqhe/ mzi015.

64. Lesar TS, Briceland LL, Delcoure K, Parmalee JC, Masta-Gornic $\mathrm{V}$, Pohl H. Medication prescribing errors in a teaching hospital. JAMA. 1990;263(17):2329-34.

65. Hodgkinson MR, Larmour I, Lin S, Stormont AJ, Paul E. The impact of an integrated electronic medication prescribing and dispensing system on prescribing and dispensing errors: a before and after study. J Pharm Pract Res. 2017;47(2):110-20.

66. Dale Ms A, Copeland R, Barton R. Prescribing errors on medical wards and the impact of clinical pharmacists. Int J Pharm Pract. 2010;11(1):19-24. https://doi.org/10.1211/002235702829.

67. Khan G, Hammond I, Holdsworth H, Dobrzanski S. The nature of hospital prescribing errors. Br J Clin Gov. 2002;7(3):187-93. https://doi.org/10.1108/14664100210438271.

68. Parke J. Risk analysis of errors in prescribing, dispensing and administering medications within a district hospital. J Pharm Pract Res. 2006;36(1):21-4. https://doi. org/10.1002/j.2055-2335.2006.tb00880.x.

69. Grasso BC, Genest R, Jordan CW, Bates DW. Use of chart and record reviews to detect medication errors in a state psychiatric hospital. Psychiatr Serv (Washington, DC). 2003;54(5):677-81. https://doi.org/10.1176/appi.ps.54.5.677.

70. Fanning L, Jones N, Manias E. Impact of automated dispensing cabinets on medication selection and preparation error rates in an emergency department: a prospective and direct observational before-and-after study. J Eval Clin Pract. 2016;22(2):156-63.

71. Dean B, Schachter M, Vincent C, Barber N. Prescribing errors in hospital inpatients: their incidence and clinical significance. Qual Saf Health Care. 2002;11(4):340-4. https://doi.org/10.1136/ qhe.11.4.340.

72. Dean B, Barber N, Schachter M. What is a prescribing error? Qual Health Care. 2000;9(4):232-7. https://doi.org/10.1136/ qhe.9.4.232.

73. Bacic Vrca V, Becirevic-Lacan M, Bozikov V, Birus M. Prescribing medication errors in hospitalised patients: a prospective study. Acta Pharm (Zagreb, Croatia). 2005;55(2):157-67.

74. Nelson CE, Selbst SM. Electronic prescription writing errors in the pediatric emergency department. Pediatr Emerg Care. 2015;31(5):368-72.

75. Vira T, Colquhoun M, Etchells E. Reconcilable differences: correcting medication errors at hospital admission and discharge. Qual Saf Health Care. 2006;15(2):122-6. https://doi. org/10.1136/qshc.2005.015347.

76. Eisenhut M, Sun B, Skinner S. Reducing prescribing errors in paediatric patients by assessment and feedback targeted at prescribers. ISRN Pediatr. 2011. https://doi.org/10.5402/2011/54568

77. Fontan JE, Maneglier V, Nguyen VX, Loirat C, Brion F. Medication errors in hospitals: computerized unit dose drug dispensing system versus ward stock distribution system. Pharm World Sci. 2003;25(3):112-7.

78. Voeffray M, Pannatier A, Stupp R, Fucina N, Leyvraz S, Wasserfallen JB. Effect of computerisation on the quality and safety of chemotherapy prescription. Qual Saf Health Care. 2006;15(6):418-21. https://doi.org/10.1136/qshc.2005.016808.

79. Walsh KE, Adams WG, Bauchner H, Vinci RJ, Chessare JB, Cooper MR, et al. Medication errors related to computerized order entry for children. Pediatrics. 2006;118(5):1872-9. https ://doi.org/10.1542/peds.2006-0810.

80. Westbrook JI, Rob MI, Woods A, Parry D. Errors in the administration of intravenous medications in hospital and the role of correct procedures and nurse experience. BMJ Qual Saf. 2011;20(12):1027-34. https://doi.org/10.1136/bmjqs-2011000089 .

81. Ridley SA, Booth SA, Thompson CM. Prescription errors in UK critical care units. Anaesthesia. 2004;59(12):1193-200. https:// doi.org/10.1111/j.1365-2044.2004.03969.x.

82. Vaidya V, Sowan AK, Mills ME, Soeken K, Gaffoor M, Hilmas E. Evaluating the safety and efficiency of a CPOE system for continuous medication infusions in a pediatric ICU. In: AMIA annual symposium proceedings AMIA symposium. 2006, p. 1128.

83. Bates DW, Cullen DJ, Laird N, et al. Incidence of adverse drug events and potential adverse drug events: implications for prevention. JAMA. 1995;274(1):29-34. https://doi.org/10.1001/ jama.1995.03530010043033.

84. Bates DW, Boyle DL, Vander Vliet MB, Schneider J, Leape L. Relationship between medication errors and adverse drug events. J Gen Intern Med. 1995;10(4):199-205.

85. Ali S, Aboheimed NI, Al-Zaagi IA, Al-Dossari DS. Analysis of medication errors at a large tertiary care hospital in Saudi Arabia: a retrospective analysis. Int J Clin Pharm. 2017;39(5):1004-7.

86. Gokhul A, Jeena PM, Gray A. Iatrogenic medication errors in a paediatric intensive care unit in Durban, South Africa. South Afr Med J. 2016;106(12):1222-9.

87. Calabrese AD, Erstad BL, Brandl K, Barletta JF, Kane SL, Sherman DS. Medication administration errors in adult patients in the ICU. Intensive Care Med. 2001;27(10):1592-8. https://doi. org/10.1007/s001340101065. 
88. Runciman WB, Roughead EE, Semple SJ, Adams RJ. Adverse drug events and medication errors in Australia. Int J Qual Health Care. 2003;15(s1):i49-59. https://doi.org/10.1093/intqhc/mzg08 5.

89. Vessal G. Detection of prescription errors by a unit-based clinical pharmacist in a nephrology ward. Pharm World Sci. 2010;32(1):59-65.

90. Sacks GS, Rough S, Kudsk KA. Frequency and severity of harm of medication errors related to the parenteral nutrition process in a large university teaching hospital. Pharmacotherapy. 2009;29(8):966-74.

91. Buckley MS, Erstad BL, Kopp BJ, Theodorou AA, Priestley G. Direct observation approach for detecting medication errors and adverse drug events in a pediatric intensive care unit. Pediatr Crit Care Med. 2007;8(2):145-52.

92. Eshetie TC, Hailemeskel B, Mekonnen N, Paulos G, Mekonnen AB, Girma T. Adverse drug events in hospitalized children at Ethiopian University Hospital: a prospective observational study. BMC Pediatr. 2015. https://doi.org/10.1186/s12887-015-0401-0.

93. Jimenez Munioz AB, Muino Miguez A, Rodriguez Perez MP, Escribano MD, Duran Garcia ME, Sanjurjo Saez M. Medication error prevalence. Int J Health Care Qual Assur. 2010;23(3):32838. https://doi.org/10.1108/09526861011029389.

94. Folli HL, Poole RL, Benitz WE, Russo JC. Medication error prevention by clinical pharmacists in two children's hospitals. Pediatrics. 1987;79(5):718-22.

95. Broome L, Cox SJ, Crill CM. Frequency and severity of errors related to neonatal and pediatric parenteral nutrition. Pharmacotherapy. 2012;32(10):e269-70.

96. Costello JL, Torowicz DL, Yeh TS. Effects of a pharmacist-led pediatrics medication safety team on medication-error reporting. Am J Health Syst Pharm. 2007;64(13):1422-6.

97. Fawaz MG, Sabri NA, Albaghdady AA, Malek FAA. Detection and prevention of medication errors in the operating rooms of a pediatric surgery department in Egypt. Int J Pharm Sci Rev Res. 2017;42(2):100-6.

98. Glanzmann C, Frey B, Meier CR, Vonbach P. Analysis of medication prescribing errors in critically ill children. Eur $\mathbf{J}$ Pediatr. 2015;174(10):1347-55. https://doi.org/10.1007/s0043 1-015-2542-4.

99. Martinez-Anton A, Ignacio Sanchez J, Casanueva L. Impact of an intervention to reduce prescribing errors in a pediatric intensive care unit. Intensive Care Med. 2012;38(9):1532-8. https://doi. org/10.1007/s00134-012-2609-x.

100. Morriss FH Jr, Abramowitz PW, Nelson SP, Milavetz G, Michael SL, Gordon SN, et al. Effectiveness of a barcode medication administration system in reducing preventable adverse drug events in a neonatal intensive care unit: a prospective cohort study. J Pediatr. 2009;154(3):363-6. https://doi.org/10.1016/j. jpeds.2008.08.025.
101. Truter A, Schellack N, Meyer JC. Identifying medication errors in the neonatal intensive care unit and paediatric wards using a medication error checklist at a tertiary academic hospital in Gauteng, South Africa. SAJCH. 2017;11(1):5-10.

102. van Doormaal JE, van den Bemt PM, Mol PG, Zaal RJ, Egberts AC, Haaijer-Ruskamp FM, et al. Medication errors: the impact of prescribing and transcribing errors on preventable harm in hospitalised patients. Qual Saf Health Care. 2009;18(1):22-7.

103. Ewig CLY, Cheung HM, Kam KH, Wong HL, Knoderer CA. Occurrence of potential adverse drug events from prescribing errors in a pediatric intensive and high dependency unit in Hong Kong: An observational study. Pediatr Drugs. 2017;19:1-9.

104. Liao TV, Rabinovich M, Abraham P, Perez S, DiPlotti C, Han $\mathrm{JE}$, et al. Evaluation of medication errors with implementation of electronic health record technology in the medical intensive care unit. Open Access J Clin Trials. 2017;9:31-40. https://doi. org/10.2147/OAJCT.S131211.

105. Watts RG, Parsons K. Chemotherapy medication errors in a pediatric cancer treatment center: prospective characterization of error types and frequency and development of a quality improvement initiative to lower the error rate. Pediatr Blood Cancer. 2013;60(8):1320-4. https://doi.org/10.1002/pbc.24514.

106. Higgins NM, Moodie EE, Gauthier J, Wong L, Potter M, Klein MB. Description of factors associated with medication errors in an HIV ambulatory care setting: the DEFEAT Study. Can J Infect Dis Med Microbiol. 2012;SA:66A-7A.

107. Santell JP, Kowiatek JG, Weber RJ, Hicks RW, Sirio CA. Medication errors resulting from computer entry by nonprescribers. Am J Health Syst Pharm. 2009;66(9):843-53.

108. Meyer-Massetti C, Cheng CM, Schwappach DL, Paulsen L, Ide B, Meier CR, et al. Systematic review of medication safety assessment methods. AJHP. 2011;68(3):227-40. https://doi. org/10.2146/ajhp100019.

109. Franklin BD, Birch S, Savage I, Wong I, Woloshynowych M, Jacklin A, et al. Methodological variability in detecting prescribing errors and consequences for the evaluation of interventions. Pharmacoepidemiol Drug Saf. 2009;18(11):992-9. https://doi. org/10.1002/pds.1811.

110. Westbrook JI, Li L, Lehnbom EC, Baysari MT, Braithwaite J, Burke $\mathrm{R}$, et al. What are incident reports telling us? A comparative study at two Australian hospitals of medication errors identified at audit, detected by staff and reported to an incident system. Int J Qual Health Care. 2015;27(1):1-9. https://doi.org/10.1093/ intqhe/mzu098.

111. Hiatt HH, Barnes BA, Brennan TA, Laird NM, Lawthers AG, Leape LL, et al. A study of medical injury and medical malpractice. N Engl J Med. 1989;321(7):480-4. https://doi.org/10.1056/ nejm198908173210725. 